\title{
Food additives and
}

\section{children's behaviour:} evidence-based policy at the margins of certainty

\author{
Jim Stevenson
}

Professor Emeritus, School of Psychology, University of Southampton, UK

\begin{abstract}
The possible effects of food additives (specifically artificial colours) have been debated for over 30 years. The evidence accumulated suggests that for some children with attention deficit hyperactivity disorder (ADHD) food colours exacerbate their condition. Two studies undertaken by a research group at the University of Southampton have extended these findings to the effects on hyperactivity in children from the general population who do not show ADHD. This article reviews the response from policy-makers to these findings and concludes that the failure to impose a mandatory ban on the six food colours in the Southampton study is inadequate and that such a ban would be an appropriate application of the precautionary principle when the evidence is considered to be at the margins of certainty.
\end{abstract}

\section{Key words}

hyperactivity; food additives; precautionary principle; evidence-based policy

\section{Introduction}

There is evidence that anti-social behaviour is becoming more prevalent in the UK (Collishaw et al, 2004). The social disruption, demands on a variety of services and the financial cost of this behaviour are considerable (Scott et al, 200I). One known antecedent of later anti-social behaviour is hyperactivity in young children (Sonuga-Barke et al, 1997). Accordingly, it is a priority to identify action that might be taken to reduce hyperactivity in children.

This article provides an account of the way a set of findings concerning the possible adverse effects on children's behaviour of certain food additives were considered and acted upon by policymakers in the UK and elsewhere. The behaviour thought to be most affected is hyperactivity, which comprises overactivity, inattention and impulsivity. Hyperactivity is known to be influenced by a wide range of biological (eg. genetic differences, low birth weight) and experiential factors (eg. institutional care) (Taylor \& Sonuga-Barke, 2008). The question of the possible adverse effects of food additives as one additional influence has been debated over the past 40 years. The position in the UK until recently was that these additives were permitted to be used in food; they were indeed sanctioned for use throughout the European Union (EU). 
The first person to raise concerns was Ben Feingold, an American paediatric allergist. He suggested that many children with symptoms of attention deficit hyperactivity disorders (ADHD) would benefit from being placed on a diet free of certain food additives, especially azo dye food colours, and also free of naturally occurring salicylates. Salicylates are aspirin-like compounds that act as plant hormones and occur in many fruits and some vegetables. These views were disseminated in his book Why Your Child is Hyperactive (Feingold, 1975).

Feingold's work led to a number of studies that attempted to test whether children with ADHD would show improved behaviour in response to this diet. In 1982, the National Institutes of Health $(\mathrm{NIH})$ considered the evidence on the effectiveness of the Feingold diet (Editorial, 1982). At this time the evidence was summarised in a meta-analysis (Kavale \& Forness, 1983). The conclusion reached by the $\mathrm{NIH}$ in 1982 was that there was no consistent evidence to support the use of the Feingold diet.

\section{Controlled trials of the effect of food colours on children with ADHD}

In the 20 years following 1982, a number of further studies were published on the effects of food colours on the behaviour of children with ADHD and other behaviour problems, leading to Schab and Trinh (2004) undertaking a quantitative metaanalysis of the evidence emerging up to 2002. They applied a number of stringent criteria concerning the minimum design requirements for a study to be included in their meta-analysis. Analysing 15 studies that had used double-blind placebo-controlled methods they concluded that an effect size of 0.28 arose from the presence of food colours in children's food.

The question of effect size is an important one in subsequent policy discussions and it is essential to clarify the interpretation of this indicator. The effect size as used by Schab and Trinh is based on the magnitude of the difference in mean behaviour scores for a group of children while receiving food colours and the mean while receiving a placebo. The units for these differences are the standard deviation of the behaviour scores obtained from pooling the scores on placebo and food colours. An effect size of 0.28 shows that the behaviour scores were on average just over a quarter of a standard deviation higher on the food colours than on placebo. It is important to recognise that this is an average figure for the group as a whole. Some children will have behaviour scores elevated by a much greater amount while others will show little or no effect. Indeed, some children may show the reverse pattern, with behaviour scores that are higher on placebo than on colours. The effect size in the Schab and Trinh meta-analysis was also statistically significant (it was greater than zero by an amount that was very unlikely to be due just to chance).

There are a number of other studies not considered by Schab and Trinh (2004) that investigated food colours as part of a wider range of food stuffs that might produce an exacerbation of ADHD symptoms (Egger et al, 1985; Kaplan et al, 1989; Carter et al, 1993; Schmidt et al, 1997; Pelsser et al, 2009). These studies also showed that food colours could act to worsen symptoms for some children with ADHD.

It must be recognised that some of the studies included in the Schab and Trinh meta-analysis were based on a small number of participants - a point made by the National Institute for Health \& Clinical Excellence (2009). However, when the studies with the smallest $\mathrm{N}$ and/or lowest quality ratings were excluded, the effect size, although reduced, was still significant $(0.21)$. On the basis of their review, Schab and Trinh concluded that 'our results strongly suggest an association between ingestion of AFCs [artificial food colours] and hyperactivity' (p430). As the following quotation indicates, however, they are cautious about making strong recommendations about the use of an AFC-free diet in the clinical management of children with extreme hyperactivity or ADHD: 'the restrictiveness of an AFC-free diet may burden hyperactive children, who are already at risk for poor psychosocial outcomes. Therefore, imposition of the diet should be done reluctantly until more certain methods have been developed to identify who is AFC-responsive' (p43I).

A key point of the Schab and Trinh review is that it is based on studies of children with ADHD or other behaviour problems. In considering this evidence, the National Institute for Health \& Clinical Excellence (2009) concluded:

'The elimination of artificial colouring and additives from the diet is not recommended as a generally applicable treatment for children and young people with ADHD.

Clinical assessment of ADHD in children and young people should include asking about foods or drinks that appear to influence their 
hyperactive behaviour. If there is a clear link, healthcare professionals should advise parents or carers to keep a diary of food and drinks taken and ADHD behaviour. If the diary supports a relationship between specific foods and drinks and behaviour, then referral to a dietitian should be offered. Further management (for example, specific dietary elimination) should be jointly undertaken by the dietitian, mental health specialist or paediatrician, and the parent or carer and child or young person.' ( $p 256)$

It is therefore becoming accepted that one of the approaches to the treatment of ADHD that should be considered is diet modification but only on the basis of detailed clinical appraisal of individual cases.

\section{Studies in the general population}

The research reviewed earlier suggests that the removal of colours (and perhaps other food stuffs) may have a beneficial effect on hyperactivity symptoms in children diagnosed with ADHD. The question of whether food additives have an impact on behaviour in children in general has been examined less extensively. We have conducted two such studies and both concerned the impact of a mix of food colours and a preservative (sodium benzoate). Hyperactivity is an aspect of behaviour that shows marked individual differences in children in the general population. It is possible that the effects of food colours identified by Schab and Trinh are limited to children with extreme hyperactivity, for instance those diagnosed with ADHD. If that were the case the implications for food policy are likely to be different than if an effect can be shown for children in general.

The policy issue here concerns the number and proportion of people in the population who are affected. In the case of the metabolic disorder phenylketonuria (PKU) only a very small proportion of the population are affected (approximately one in 15,000 births) ( $\mathrm{NIH}, 2000)$. These children have a severe adverse response to the presence of phenylalanine (an amino acid) in their diet, which can result in a severe learning disability. This vulnerability of phenylalanine is determined by a genetic polymorphism; that is, the child has an atypical version of the PKU. The polymorphism can be detected from a heel prick blood sample. The public health response to this issue is to identify vulnerable individuals at birth or soon afterwards via universal screening and, if they are found to be carrying the risk allele of the gene (ie. the version of the gene that makes the child unable to metabolise phenylalanine), to place the child on a severely restricted diet free of phenylalanine. Foods such as meat, fish, eggs, milk, cheese, nuts and pulses are excluded. Vegetables and fruit are allowed in small, regulated amounts. Special low protein bread, pasta, biscuits and flour are used to supplement the diet and ensure adequate calorie intake.

A similar approach is taken with other foods that have adverse effects on a limited segment of the population, for example peanut allergy and celiac disease. The onus is on the 'at risk' individual to avoid exposure. However, if a significant proportion of the population are 'at risk' then an alternative approach might be taken to remove this substance from food, especially if it is a component of food that has no nutritional value, as is the case with food colours. It was to test this notion that the following two studies were undertaken.

\section{Isle of Wight Study}

The research group at the University of Southampton has undertaken two separate studies examining the question of the impact of food additives on behaviour of children from the general population. The first of these was undertaken with colleagues from the David Hyde Centre, St. Mary's Hospital, on the Isle of Wight. The study used a double-blind placebocontrolled crossover food challenge design with 277 three-year-old children. The study was designed to test whether the level of hyperactivity shown by children, or their atopic status (allergic sensitivity), influenced the effects of food additives on behaviour (Bateman et al, 2004). Atopy was established using a skin prick test at the time of the child's routine health check. A total of 1873 children were screened for elevated hyperactivity using two parent-completed questionnaires: the EAS Temperament Questionnaire (Buss \& Plomin, 1984) and the Weiss-Werry-Peters Activity Scale (Routh, 1978). Of these children, 1246 were also screened for atopy. This provided children for a two (high/low hyperactivity) $x$ two (atopic/non-atopic) four-group design. Using a sample recruited from the general population, this Isle of Wight Study aimed to identify whether either of these factors (elevated hyperactivity and atopy) contributed to a vulnerability to the effects of additives on behaviour. 
After an initial assessment of the level of hyperactivity shown by each child while on their usual diet, the family was advised on ways the child could eat without consuming the target additives in the trial. The child was then maintained on this 'withdrawal diet' for the remainder of the study. During the next four weeks, the child was reassessed for hyperactivity during a week with no challenges and then over the subsequent three weeks when the child took a drink prepared by the research team. The drink was made up of fruit juices alone (placebo) or a drink identical in colour, taste and smell but which contained a mix of food colours and sodium benzoate. This is referred to as Mix A and contained four colours - sunset Yellow (EI I0), tartrazine (EI02), carmoisine (EI22) and ponceau 4R (EI24) - and sodium benzoate (a preservative) (E2I I). These are all additives that are commonly found in children's food. Each child experienced one week with Mix A and one with placebo (in a randomly allocated order), with a wash-out period with no challenge drinks in between.

The findings from the Isle of Wight study were that using parent ratings of behaviour, the levels of hyperactivity were significantly higher on Mix A than on placebo. This effect could not be detected on the measures of behaviour obtained in the clinic (full details of these assessments by parents and in the clinic are given in Bateman et al, 2004). The adverse effect of Mix A was not moderated by either the child's pre-trial level of hyperactivity or by their atopic status. Not all children responded adversely to the additives but the study was unable to identify any social or biological factor that might differentiate the responders from the nonresponders. The paper by Bateman and colleagues (2004), in which the results are presented, established for the first time that a cocktail of food additives could elevate the hyperactivity levels of children in the general population.

In 2007, these results were appraised by the Committee on Toxicity (COT), which is the body that advises the UK Food Standards Agency (FSA) and thereby the UK Government on matters of food safety. They concluded that the results were consistent with published reports of behavioural changes occurring in some children following consumption of particular food additives. However, they considered that it was not possible to reach firm conclusions about the clinical significance of the observed effects and that further research was needed. The FSA put out a tender for a second study, which was awarded to the Southampton team.

\section{Southampton Study}

This second investigation was broadly similar in design to the Isle of Wight Study but involved both three- and eight to nine-year-old children and had augmented assessment of behaviour, including direct observation made in either the Early Years setting or the junior school classroom (McCann et al, 2007). The design was more complex through the introduction of a second mix of colours (Mix B). The colours in Mix B represented those most commonly found in children's food and were at a higher dose than those in Mix A. Mix B included sodium benzoate as $\operatorname{did}$ Mix $A$. The colours in Mix $B$ were sunset yellow (EII0), carmoisine (EI22), quinoline yellow (EI04) and allura red AC (EI29).

Children were assessed at baseline on a hyperactivity measure. This was an aggregate of parent and teacher ratings, counts based on direct observation of behaviour and a computerised test of attention (the latter was used for the eight to nine-year-old children only). As with the Isle of Wight study, children were recruited from the general population to take part but on this occasion from Early Years settings and junior schools in the Southampton area. A total of 153 three-year-old and 144 eight to nine-year-old children took part in the study. For full details of the methods used in this study see McCann and colleagues (2007).

The Southampton Study replicated the Isle of Wight Study in finding elevated levels of hyperactivity when three-year-old children were given Mix A. It was also found that Mix $B$ had a significant effect on worsening the hyperactivity of eight to nine-year olds. The overall pattern of results was clear, namely that hyperactivity levels were higher on both mixes at both ages than when the children received placebo but this did not reach the $5 \%$ level of significance in all analyses. As with the Isle of Wight Study, not all children showed an adverse effect of additives on behaviour. The average effect size of additives on behaviour was 0.18 . This effect size is similar to that shown in the Schab and Trinh (2004) metaanalysis by the larger, better-designed studies of children with ADHD where the effect size was 0.21 .

The COT considered the findings of this study again and concluded:

'We consider that this study has provided supporting evidence suggesting that certain mixtures of artificial food colours together with the preservative sodium benzoate are 
associated with an increase in hyperactivity in children from the general population. If causal, this observation may be of significance for some individual children across the range of hyperactive behaviours, but could be of more relevance for children towards the more hyperactive end of the scales.' ( $p \mid 2)$

'We conclude that the results of this study are consistent with, and add weight to, previous published reports of behavioural changes occurring in children following consumption of particular food additives.' ( $/ 2$ )

Both quotations from: http://cot.food.gov. uk/pdfs/colpreschil.pdf

Thus far the article has summarised the research evidence to date on the impact of certain food additives (especially colours) on behaviour. The issue of how policy-makers have responded to this evidence will now be considered.

\section{EFSA review and EU Parliament}

Under EU law, jurisdiction on matters of food safety is an EU competence; that is, it is the responsibility of the EU Parliament rather than sovereign governments. For this reason, the FSA referred the evidence related to additives and behaviour to the European Food Standards Authority (EFSA). The EFSA Panel on Food Additives, Flavourings, Processing Aids and Food Contact Materials set up an Expert Working Party to consider this evidence. This scrutiny, which included an independent re-analysis of the data, supported the conclusion from the Southampton team that the mixtures of additives had a measurable effect on the activity and attention of some children. The average effects for children as a whole are small but there is considerable variation, with some children responding more and others less. The panel recognised that the Southampton Study was the largest of its kind and one of few to be based on children from the general population. Further, the results on three-year-olds replicated the findings of a previous study.

However, the EFSA Panel concluded that the results of the study could not be used as a basis for changing the recommended levels (Acceptable Daily Intake, ADI) for the food colours or the sodium benzoate preservative. The EFSA Panel described the effects in the Southampton study as small and their significance for children's development and education uncertain. In a rejoinder, the Southampton team suggested that since the colours being tested in this study are of no nutritional value, even the small overall benefit of removing them from children's diets would come at no cost or risk to the child. Under these circumstances a benefit, even a small one, would be worthwhile achieving. Added weight is given to this counter-argument because other important influences on hyperactivity in children, such as genetic factors, are difficult to address whereas the risk arising from exposure to food colours can be regulated.

The EU Parliament decided that the findings from the Southampton Study did warrant a legislative change. In July 2008 , it decided that it would require manufacturers to label foods containing the six colours with the following warning: 'may have an adverse effect on activity and attention in children'.

\section{Food Standards Agency response}

When the Southampton Study findings were published in The Lancet in September 2007 (McCann et al, 2007) the initial response from the FSA was to revise their advice, suggesting parents avoid the six food colours if they were concerned that their child might be showing elevated levels of hyperactivity. The FSA then awaited the response from the EFSA in March 2008 before making a decision on the issue by their board. In April 2008, the board decided to revise their advice to parents (Box I).

Subsequently, in November 2008 ministers in the UK Government indicated their support for a voluntary ban in the UK on these six commonlyfound colours as from the end of 2009.

\section{Limitations on evidence}

There are limitations on what is known about the impact of food colours on children in the general population. It is not known whether there is a different cumulative risk of repeated and longterm exposure to colours. The Isle of Wight and Southampton Studies demonstrated the effects of short-term (one-week) exposure. Interestingly, the Southampton Study showed that the effects were reversible in that there was no carry-over effect from a previous exposure on behaviour shown in a subsequent challenge week following a one-week washout period on a placebo challenge.

The Isle of Wight and Southampton Studies examined the effects of a cocktail of food colours and a preservative. The impact of individual 


\section{Box 1 FSA advice to parents on food colours and hyperactivity}

Hyperactivity is a general term used to describe behavioural difficulties affecting learning, memory, movement, language, emotional responses and sleep patterns. Attention deficit hyperactivity disorder (ADHD) is more than just hyperactive behaviour. Parents with children who have ADHD should consult their own doctor for further advice.

Research funded by the FSA has suggested that consumption of mixes of certain artificial food colours and the preservative sodium benzoate could be linked to increased hyperactivity in some children. It is important to remember that hyperactivity is also associated with many other factors in addition to certain additives, so dietary advice may help manage hyperactive behaviour but may not be the total solution. Other factors include premature birth, genetics and upbringing.

If your child shows signs of hyperactivity, or if on the basis of this information you have concerns, you might choose to avoid giving your child food and drinks containing the following artificial colours:

sunset yellow FCF (E110)

quinoline yellow (E104)

carmoisine (E122)

allura red (E129)

tartrazine (E102)

ponceau 4R (E124)

These colours are used in a wide range of foods that tend to be brightly coloured, including some soft drinks, sweets, cakes and ice cream. Parents may wish to check the labels of brightly coloured foods if they want to avoid certain colours. When colours are used in food, they must be declared in the list of ingredients a 'colour', plus either their name or $\mathrm{E}$ number. The Action on Additives website contains a list of some foods which contain the above colours (see below). [www.actiononadditives.com]

If you buy any foods that are sold without packaging you will need to check with the person selling the product or with the manufacturer.

Some manufacturers and retailers have told the Agency that they are already working towards finding alternatives to these colours. The Agency is encouraging manufacturers to take further action and the use of colours in products may therefore change. http://www/food.gov.uk/safereating/chemsafe/additivesbranch/colours/hyper/

components of this cocktail is unknown. McCann and colleagues (2007) drew attention to the need for a study of the effects on behaviour of sodium benzoate alone.

\section{Guiding policy under uncertainty}

A crucial aspect of the results of the Southampton study is that they extend the findings reviewed by Schab and Trinh (2004) to children from the general population. The findings are consistent with a causal effect of the mixtures on hyperactivity. The effects were shown in a randomised controlled trial (the clinical research equivalent of the 'experiment' - the touchstone demonstration of causality). Moreover, since the study was designed as a within-subject crossover trial there are no between-groups artefacts that might confound the attribution of effects to additive exposure.
The only likely threat to the internal validity of the study is the possibility that some of the measurements were made not blind as to which mixtures had been used week by week. The rigorous control applied in the study will have prevented anyone responsible for measurements being aware of the mixtures being taken by the child at any one time. Moreover, repeated tests were made to show that the drinks containing the different mixtures could not reliably be differentiated. This leads us to conclude that the effects we identified demonstrate a causal role of food additives on hyperactivity in the general population. However, they are just one contributor to a wide range of influences on hyperactivity.

Accepting this causal role, the next question is to determine the risk it presents to children. There is a low hazard for most children of the 
mixtures tested insofar as the effects of the additives are small. However, in appraising what action is appropriate there is a need to consider hazard, exposure and risk. In terms of exposure, these food additives are widely present in foods ingested by children, including confectionery, cakes, biscuits and soft drinks. The food industry itself has recognised the need to reduce exposure and manufacturers have voluntarily been reducing the levels of artificial colours in food products. Nevertheless, at present children are still ubiquitously exposed to this hazard.

If the hazard is low but the exposure is high, what does that mean for risk? It is well established that ADHD is a risk factor for later conduct disorders and reading disability (Taylor \& Sonuga-Barke, 2008). The key here is whether the effects identified in the Southampton study are of developmental significance to the child when the levels of hyperactivity fall short of that needed for an ADHD diagnosis. Elevated levels of hyperactivity in young children represent a risk for continuing behaviour problems into later childhood (Sonuga-Barke et al, 1997; Danckerts et al, 2000). It should also be recognised that children with elevated levels of hyperactivity can be disruptive to a family and are sometimes socially isolated because peers find their behaviour unsettling (Blachman \& Hinshaw, 2002). Moreover, studies have established a relationship across the full range of hyperactivity scores with later outcomes, as the following quotation indicates:

'There were strong linear relationships between early hyperactivity and later adverse outcomes. Adjustment for other childhood variables suggested that early hyperactivity was associated with continuing school difficulties, problems with attention and poor reading in adolescence.' (McGee et al, 2002, pl004)

In formulating policy on public health harm, consideration has to be given to the putative hazard, in other words the degree of exposure and the risk to future well-being that is likely to arise from such an exposure. Exposure to food colours is ubiquitous. However, it should be noted that the use of azo dyes by UK food manufacturers has been decreasing. Indeed, in part as a response to the Isle of Wight and Southampton Studies, retailers and manufacturers have been using 'free of artificial colours' as a marketing feature for their goods. Therefore, in terms of a public health formulation of harm, there is evidence that food colours produce a small hazard with high exposure that presents an educationally significant long-term risk to the child.

The case of food colours throws up general questions concerning legislating for hazards. All the evidence suggests that many children are not affected by exposure to additives. One response, then, is to place the onus on the individual (or in this case on the parents) to avoid exposure if adverse reactions are suspected. In the case of food colours, the FSA directed such advice specifically to parents whose children were hyperactive (ie. had a high level of hyperactivity).

For children showing ADHD there has been a recently published review and guidelines (National Institute for Health and Clinical Excellence, 2008). This concluded that:

'epidemiological research indicates a link between additives and preservatives in the diet and levels of hyperactivity (McCann et al, 2007); and at least a small proportion of children with $A D H D$ demonstrate idiosyncratic reactions to some natural foods and/or artificial additives, and may be helped by a carefully applied exclusion diet.' (National Institute for Health and Clinical Excellence, 2008, p30).

However, it did not recommend exclusion diets as a standard treatment for ADHD. As it currently stands, until the voluntary ban requested by the UK is universal, parents who think that their child's behaviour might be affected by colours will have to inspect the warning labels being adopted in the EU.

An alternative to this imposition of responsibility on individual parents to regulate their child's exposure is simply a mandatory universal ban of these colours. The argument for making this universal is based on the fact these colours are not functional and can readily be replaced by innocuous alternatives. Most importantly, the effects on children are sufficiently common and sufficiently marked to create a change in the population mean hyperactivity level to a 'clinically relevant' degree, according to the COT. Under these circumstances it would appear highly desirable to ban these colours from food.

It has been recognised that when faced with uncertainty about risks the precautionary principle should be invoked, although to date this concept has been applied more often to broad environmental issues rather than to human health. The principle is defined as follows: 
'The Precautionary Principle is one of the key elements for policy decisions concerning environmental protection and management. It is applied in the circumstances where there are reasonable grounds for concern that an activity is, or could, cause harm [sic] but where there is uncertainty about the probability of the risk and the degree of harm.' http://www.jncc.gov. uk ( $\mathrm{p} \mid 575)$

Such reasoning led Schab and Trinh (2004) to conclude that:

'as long as we remain uncertain about the early and long-term effects of these exposures, society should engage in a broader discussion about whether the aesthetic and commercial rationale for the use of AFCs is justified' (p43I).

The position in relation to AFCs is analogous to the state of knowledge about lead and IQ in children that was being evaluated in the early 1980s. Needleman and colleagues (1979) found the difference in IQ between high and low lead groups of children was 4.5 IQ points (I06.6 vs. 102. I). Using a standard deviation of 15 this gives an effect size of 0.3. Later, Needleman (1983) reported that this difference fell by two points when confounding social differences were taken into account. This produced an effect size of 0.17. This is very close to the effect sizes obtained in the study of food additives.

In response to these findings on lead, Rutter (1983) concluded:

'A marked reduction in the level of environmental lead is likely to make an important difference to some children. Moreover it is important to recognise that a small change in mean $I Q$ or average behaviour of the population as a whole will have a much greater effect at the extremes of the distribution [...]. Accordingly actions to cut down the amount of lead pollution of the environment should be worthwhile; there is sufficient justification for action now' (p364).

This evidence resulted in subsequent action to remove lead from petrol and the adoption of 10 $\mathrm{mu} \mathrm{g} / \mathrm{dL}$ as a maximum level for blood lead. Later studies have shown that adverse effects of elevated lead on behaviour and cognition can actually be detected below this level (Lanphear et al, 2005) and it has been argued that the maximum level should be reduced by a factor of 5 to $2 \mathrm{mu} g / \mathrm{dL}$ (Gilbert \& Weiss, 2006).

The precautionary principle was adopted in relation to lead and the subsequent evidence indicates that this was a prudent action to take. It makes sense to introduce a mandatory ban on artificial food colours (at least the six examined in the Southampton Study), particularly because the costs of making the change are low, natural colour alternatives are readily available and the functional benefits of these food additives are negligible. The contribution this might make to reducing the risk of later anti-social behaviour and to reducing the associated social and financial cost (Scott et al, $200 \mathrm{I})$ gives further weight to this argument.

\section{Implications for future policy}

The procedures for regulating food safety are firmly rooted in the principles of toxicology, with a heavy reliance on either looking for biological tissue changes through animal testing or increasingly using cells. The vision for toxicology testing in the 2 I st century produced by the National Research Council of the National Academies (2007) emphasises this approach as follows:

'transform toxicity testing from a system based on whole-animal testing to one founded primarily on in vitro methods that evaluate changes in biologic processes using cells, cell lines, or cellular components, preferably of human origin' ( $\mathrm{Pl}$ )

It has been recognised by others that methods for testing effects on human behaviour and brain functions are less well-developed, in particular in relation to the risks to children's well-being (Weiss, 2000; Rice, 2005). What is needed is a commitment to consider a broader range of potential harm when adjudicating on food safety. In terms of children's well-being this means extending the notion of toxicity from damage to the central nervous system (neurotoxicity) to include effects on brain function as assessed in behavioural toxicity (Cory-Slechta, Weiss \& Cranmer, 2008).

\section{Acknowledgements}

The Isle of Wight and Southampton Studies were funded by the UK Ministry of Agriculture, Fisheries and Food and the Food Standards Agency respectively. The views expressed in this paper are those of the author alone and not necessarily those of the funding agencies. 


\section{Summary of policy and practice implications}

- Dietary changes, including the removal of food colours, can be considered as a possible approach to the treatment of children with ADHD but one that should only be undertaken with close nutritional supervision based on the recently published NIHCE guidelines.

- The evidence suggests that a mandatory ban on food colours in the UK would be preferable to the current voluntary ban.

- The methods for testing the effects of food and food additives on human behaviour and brain functions are under-developed, in particular in relation to the risks to children's well-being. What is needed is a commitment to consider a broader range of potential harm when adjudicating on food safety. In terms of children's well-being this means extending the notion of toxicity from damage to the central nervous system (neurotoxicity) to include effects on brain function as assessed in behavioural toxicity.

\section{Address for correspondence}

Professor Jim Stevenson

School of Psychology

University of Southampton

Highfield

Southampton

SOI7 IBJ

UK

Email: jsteven@soton.ac.uk

\section{References}

Bateman B, Warner JO, Hutchinson E, Dean T, Rowlandson P, Gant C, Grundy J, Fitzgerald C \& Stevenson J (2004) The effects of a double-blind, placebo-controlled, artificial food colourings and benzoate preservative challenge on hyperactivity in a general population sample of preschool children. Archives of Disease in Childhood 89 506-5II.

Blachman DR \& Hinshaw SP (2002) Patterns of friendship among girls with and without attentiondeficit/hyperactivity disorder. Journal of Abnormal Child Psychology 30 625-640.

Buss AR \& Plomin R (1984) Temperament: Early Developing Personality Traits. Hillsdale, NJ: Erlbaum.

Carter CM, Urbanowicz M, Hemsley R, Mantilla L, Strobel S, Graham PJ \& Taylor E (1993) Effects of a food diet in attention deficit disorder. Archives of Disease in Childhood 69 564-568.
Cohen J (1988) Statistical Power Analysis for The Behavioural Sciences (2 ${ }^{\text {nd }}$ edition). Hillsdale, NJ: Erlbaum.

Collishaw S. Maughan B, Goodman R \& Pickles A (2004) Time trends in adolescent mental health. Journal of Child Psychology and Psychiatry 45 I350-1362.

Cory-Slechta DA, Weiss B \& Cranmer J (2008) The environmental etiologies of neurobehavioral deficits and disorders: weaving complex outcomes and risk modifiers into the equation. Neurotoxicology 29 759-760.

COT (Committee on Toxicity) (2007) Statement on Research Project (T07040) investigating the effect of mixtures of certain food colours and a preservative on behaviour in children. London: COT Committee on Toxicity. Available from: http://www.food.gov.uk/ multimedia/pdfs/committee/colpreschil.pdf (accessed September 2009).

Danckaerts M, Heptinstall E, Chadwick O, Taylor E (2000) A natural history of hyperactivity and conduct problems: self-reported outcome. European Child \& Adolescent Psychiatry 9 26-38.

Editorial (1982) NIH consensus development conference: defined diets and childhood hyperactivity. Clinical Pediatrics 21 627-30.

Egger J, Carter CM, Graham PJ, Gumley D \& Soothill JF (1985) Controlled trial of oligoantigenic treatment in the hyperkinetic syndrome. The Lancet I 540-545.

Feingold B (1975) Why Your Child is Hyperactive. New York: Random House.

Gilbert SG \& Weiss B (2006) A rationale for lowering the blood lead action level from 10 to $2 \mathrm{mu} g / \mathrm{dL}$. Neurotoxicology 27 693-70I.

Joint Nature Conservation Committee (JNCC) (2009) Website. Available from: http://www/jncc.gov.uk/ default.aspx?page $=1575$ (accessed September 2009).

Kaplan BJ, McNicol J, Conte RA \& Mogjadam HK (1989) Dietary replacement in preschool-aged hyperactive boys. Pediatrics 83 7-17.

Kavale A \& Forness SR ( 1983) Hyperactivity and diet treatment: a meta-analysis of the Feingold hypothesis. Journal of Learning Disabilities 16 324-330.

Lanphear BP, Hornung R, Khoury J, Yolton K, Baghurstl $P$, Bellinger DC, Canfield RL, Dietrich KN, Bornschein R, Greene T, Rothenberg SJ, Needleman HL, Schnaas L, Wasserman G, Graziano J \& Roberts R (2005) Low-level environmental lead exposure and children's intellectual function: an international pooled analysis. Environmental Health Perspectives II 3 894-899.

McCann D, Barrett A, Cooper A, Crumpler D, Dalen L, Grimshaw K, Kitchen E, Lok K, Porteous L, Prince E, Sonuga-Barke E, Warner JO \& Stevenson J (2007) Food additives and hyperactive behaviour in 3-year-old and 8/9-year-old children in the community: a randomised, double-blind, placebo-controlled trial. The Lancet 3 |560-1567. 
McGee R, Prior M, Williams S, Smart D \& Sanson A (2002) The long-term significance of teacher-rated hyperactivity and reading ability in childhood: findings from two longitudinal studies. Journal of Child Psychology and Psychiatry 43 1004-1017.

Needleman HL, Gunnoe C, Leviton A, Reed R, Peresie H, Maher C \& Barrett P (1979) Deficits in psycholgic and classroom performance of children with elevated dentine lead levels. New England Journal of Medicine 300 689-695.

Needleman H (1983) The neuropsychological consequences of low-level exposure to lead in childhood. In: M Rutter and R Russell Jones (Eds) Lead Versus Health: Sources and effects of low lead exposure. Chichester: John Wiley.

$\mathrm{NIH}$ (National Institutes of Health) (2000) Phenylketonuria: screening and management. National Institutes of Health Consensus Statement $I 7$ (3) I-28.

National Institute for Health \& Clinical Excellence (2008) Diagnosis and Management of ADHD in Children, Young People and Adults. Attention deficit hyperactivity disorder. NICE clinical guideline 72. London: National Institute for Health \& Clinical Excellence. Available from: http://www.nice.org.uk/nicemedia/pdf/ CG072NiceGuidelineV2.pdf (accessed September 2009).

National Institute for Health \& Clinical Excellence (2009) Diagnosis and Management of ADHD in Children, Young People and Adults. National Clinical Practice Guideline Number 72 Full Guidance. London: British Psychological Society and Royal College of Psychiatrists. Available from: http://www.nice.org.uk/nicemedia/pdf/ ADHDFullGuideline.pdf (accessed September 2009).

National Research Council of The National Academies (2007) Toxicity Testing in the 2 Ist Century: A Vision and a Strategy. Washington, DC: The National Academies Press.

Pelsser LMJ, Frankena K, Toorman J, Savelkoul HFJ, Pereira RR, Buitelaar JK (2009) A randomised controlled trial into the effects of food on ADHD. European Child \& Adolescent Psychiatry 18 12-19.

Rice DC (2005) Assessing the effects of environmental toxicant exposure in developmental epidemiological studies: issues for risk assessment. Neurotoxicology 26 483-489.
Routh D ( 1978) Hyperactivity. In: P Magrab (Ed) Psychological Management of Pediatric Problems (pp3-8) Baltimore: University Park Press.

Rutter M (1983) Low level lead exposure: sources, effects and implications. In: M Rutter \& R Russell Jones (Eds) Lead Versus Health: Sources and Effects of Low Lead Exposure. Chichester: John Wiley.

Schab DW \& Trinh NHT (2004) Do artificial food colours promote hyperactivity in children with hyperactive syndromes? A meta-analysis of double-blind placebo-controlled trials. Journal of Developmental and Behavioural Pediatrics 25 423-434.

Schmidt MH, Mocks P, Lay B, Eisert HG, Fojkar R, Fritz-Sigmund D, Marcus A \& Musaeus B (1997) Does oligoantigenic diet influence hyperactive/conductdisordered children: a controlled trial. European Child and Adolescent Psychiatry 6 88-95.

Scott S, Knapp M, Henderson J \& Maughan B (200I) Financial cost of social exclusion: follow-up study of antisocial children into adulthood. British Medical Journal $32319 \mid-194$.

Sonuga-Barke EJS, Thompson M, Stevenson J \& Viney D (1997) Patterns of behaviour problems among preschool children. Psychological Medicine 27 909-918.

Taylor E \& Sonuga-Barke EJS (2008) Disorders of attention and activity. In: M Rutter, D Bishop, D Pine, S Scott, J Stevenson, E Taylor \& A Thapar (Eds) Rutter's Child and Adolescent Psychiatry ( $5^{\text {th }}$ edition). Oxford: Blackwell-Wiley.

Weiss B (2000) Vulnerability of children and the developing brain to neurotoxic hazards. Environmental Health Perspectives 108 375-38I.

\section{About the author}

Jim Stevenson is Professor Emeritus at the Developmental Brain Behaviour Laboratory at the School of Psychology, University of Southampton. He has undertaken a wide range of studies on developmental psychopathology and on developmental disorders in children, examining both social and biological influences on atypical development. 